\title{
Association of Educational Level and Marital Status With Obesity: A Study of Chinese Twins
}

\author{
Chunxiao Liao, ${ }^{1}$ Wenjing Gao, ${ }^{1}$ Weihua Cao, ${ }^{1}$ Jun Lv, ${ }^{1}$ Canqing Yu, ${ }^{1}$ Shengfeng Wang, ${ }^{1}$ Chunxiao Li, ${ }^{1}$ \\ Zengchang Pang, ${ }^{2}$ Liming Cong, ${ }^{3}$ Zhong Dong, ${ }^{4}$ Fan Wu, ${ }^{5}$ Hua Wang, ${ }^{6}$ Xianping Wu, ${ }^{7}$ Guohong Jiang, ${ }^{8}$ \\ Xiaojie Wang, ${ }^{9}$ Binyou Wang, ${ }^{10}$ and Liming $\mathrm{Li}^{1}$ \\ ${ }^{1}$ Department of Epidemiology and Biostatistics, School of Public Health, Peking University, Beijing, China \\ ${ }^{2}$ Qingdao Center for Diseases Control and Prevention, Qingdao, China \\ ${ }^{3}$ Zhejiang Center for Disease Control and Prevention, Hangzhou, China \\ ${ }^{4}$ Center for Chronic Disease Prevention, Beijing Center for Disease Control and Prevention, Beijing, China \\ ${ }^{5}$ Shanghai Center for Disease Control and Prevention, Shanghai, China \\ ${ }^{6}$ Jiangsu Center for Disease Control and Prevention, Nanjing, China \\ ${ }^{7}$ Sichuan Center for Disease Control and Prevention, Chengdu, China \\ ${ }^{8}$ Center for Chronic Disease Prevention, Tianjin Center for Disease Control and Prevention, Tianjin, China \\ ${ }^{9}$ Qinghai Center for Disease Control and Prevention, Xining, China \\ ${ }^{10}$ Department of Epidemiology and Biostatistics, School of Public Health, Harbin Medical University, Harbin, China
}

The prevalence of overweight and obesity is growing rapidly in many countries. Socioeconomic inequalities might be important for this increase. The aim of this study was to determine associations of body mass index (BMI), overweight and obesity with educational level and marital status in Chinese twins. Participants were adult twins recruited through the Chinese National Twin Registry (CNTR), aged 18 to 79 years, and the sample comprised 10,448 same-sex twin pairs. Current height, weight, educational attainment, and marital status were self-reported. Regression analyses and structural equation models were conducted to evaluate $\mathrm{BMI}$, overweight, and obesity associated with educational level and marital status in both sexes. At an individual level, both educational level and marital status were associated with higher $\mathrm{BMI}$ and higher risk of being overweight and obesity in men, while in women the effects of educational level on BMI were in the opposite direction. In within-Monozygotic (MZ) twin-pair analyses, the effects of educational level on BMI disappeared in females. Bivariate structural equation models showed that genetic factors and shared environmental confounded the relationship between education and BMI in females, whereas marital status was associated with BMI on account of significant positive unique environmental correlation apart in both sexes. The present data suggested that marital status and BMI were associated, independent of familiar factors, for both sexes of this study population, while common genetic and shared environmental factors contributed to education-associated disparities in BMI in females.

Keywords: education, marital status, obesity, twin study, genetic

China has undergone increasing changes in the prevalence of obesity in recent decades. During the period of 1993 to 2009, the prevalence of obesity (body mass index (BMI) $\geq 27.5 \mathrm{~kg} / \mathrm{m}^{2}$ ) increased from $4.0 \%$ to $10.7 \%$ in Chinese adults (Xi et al., 2012).

Obesity has been reported to be associated with various indicators of socioeconomic status, such as educational attainment, marital status, occupation, and income level (Gupta et al., 2012; Silva, 2013). Unlike income or occupation, educational levels are stable and can be assessed for all individuals, and are useful across the age spectrum (Tzotzas et al., 2010). Emerging evidence has shown that BMI differs by educational levels, with better educated individuals tend- ing to have better health and a lower risk of obesity (Boing \& Subramanian, 2015; Hermann et al., 2011). However, the

RECEIVED 28 November 2017; ACCEPTED 30 January 2018

ADDRESS FOR CORRESPONDENCE: Liming Li, Department of Epidemiology and Biostatistics, School of Public Health, Peking University, 38 XueYuan Rd., HaiDian District, Beijing 100191, China. E-mail: lmlee@vip.163.com.

Wenjing Gao, Department of Epidemiology and Biostatistics, School of Public Health, Peking University, 38 XueYuan Rd., HaiDian District, Beijing 100191, China. E-mail: pkuepigwj@ 126.com 
relationship between educational level and obesity may vary in industrialized and developing countries. While a consistent inverse association between education and obesity was found especially for women in developed countries, there is less evidence from developing countries. In addition, marital status has also been reported to have mixed relationships with obesity. Although most studies tend to find that married people more often have a higher BMI than those living alone, important variations exist according to sex and ethnicity (Sobal et al., 2003; Sobal et al., 2009).

Although a link between socioeconomic status and obesity status has been suggested, the relevant mechanism is still poorly understood. Socioeconomic status may influence BMI in a direct way since both men and women of a higher social class appear to be more concerned about their health (Wardle \& Griffith, 2001) and have more positive attitudes to healthy lifestyles (Wardle \& Steptoe 2003). Another possible reason may be that people in a better socioeconomic environment might also have unobserved factors that are important for health. As shown by previous studies, many factors in childhood, such as poorer residential areas and social deprivation (Nau et al., 2015), have been found to be associated with obesity and are probably more prevalent in lower socioeconomic positions. Moreover, common genetic factors may affect both BMI and socioeconomic status. Previous studies have shown that BMI is highly heritable (Schousboe et al., 2003; Silventoinen et al., 2017), and there is also a genetic component underlying socioeconomic factors, such as educational attainment (Heath et al., 1985) and marital status (Johnson et al., 2004). It is possible that some of the genetic factors predisposing to BMI may also account for genetic variation in these socioeconomic factors. Therefore, the crucial research question was whether the so-called gradients in health by socioeconomic factors are causal effects of these factors or the result of unobserved familial or genetic factors correlated with higher levels of social class. Better comprehension of the causal mechanisms underlying socioeconomic disparities in obesity would help to identify risk groups and formulate measures that might be used to reduce obesity among disadvantaged persons.

Twin design is seen as a useful method of controlling confounders in observational epidemiologic studies. Monozygotic (MZ) twins are perfectly matched for genetic and childhood family environmental factors, while dizygotic (DZ) twins share on average half of their genes and their entire family environment. As such, comparing twins within pairs can provide powerful control for genetic and shared environmental confounding factors that are typically different among unrelated individuals (McGue et al., 2010). Twin studies examining the relation between socioeconomic indicators with obesity or other health outcomes are sparse, and few have been conducted in Asian populations. In general, the current evidence has remained inconclusive. A study using a Finnish twin sample examining education-associated disparities in weight and weight gain indicated that common genetic factors affecting both educational attainment and body weight contributed to their associations (Silventoinen et al., 2004). Another Australian twin study reported that the association between education and the probability of being overweight was significant in male twins, independent of genetic influence (Webbink et al., 2010).

Since the association of socioeconomic status with obesity and the etiology behind this association are still poorly understood, we aimed to evaluate the associations of BMI, overweight, and obesity with socioeconomic status as indexed by educational level and marital status in 18- to 79-year-old adult twins from the Chinese National Twin Registry (CNTR). We also investigated whether shared genetic and environmental factors contributed to the socioeconomic disparities in BMI.

\section{Methods}

\section{Study Sample}

The data were derived from the CNTR. During 20112012, twin members were recruited for this study through in-person interview by means of a questionnaire in nine provinces or cities, including Jiangsu, Zhejiang, Sichuan, Heilongjiang, and Qinghai provinces, and the cities of Tianjin, Beijing, Qingdao, and Shanghai; detailed information about this twin registry is described elsewhere ( $\mathrm{Li}$ et al., 2013). All complete same-sex twin pairs aged between 1879 years who replied to the questionnaires in 2011-2012 with information about education, marital status, and BMI were included in this study. Twin pairs were excluded from analyses if one of the co-twins was diagnosed with cardiovascular heart disease, stroke, type 2 diabetes, or cancer. Twins reared apart were excluded from analyses (reared apart was defined according to SATSA's definition as twins who had been reared apart for at least 1 year before the age of 11). Finally, 10,448 complete adult twin pairs were eligible for this study.

The determination of zygosity was based on age, sex, questions of appearance confused by strangers, and previously perceived zygosity from questionnaires. This method has been validated using DNA genotyping from 192 pairs of same-sex twins and found to have a mean area under curve (AUC) of 89.03\% (Wang et al., 2015).

All participants provided informed consent and the Biomedical Ethics Committee at Peking University, Beijing, China approved the study protocol.

\section{Measures}

Explanatory variables. Data on education were selfreported. In the questionnaire, educational status was evaluated by asking the participants to declare their highest level of educational achievement. Educational level was grouped into three categories: (a) illiterate or primary 
education, (b) secondary education, and (c) tertiary education. Marital status was assessed by asking whether participants were unmarried, married, separated, divorced, or widowed.

Outcome variables. Self-reported height and weight were used to calculate BMI. Data on height and weight were required to be accurate to the nearest centimeter and kilogram, respectively. BMI was defined as weight in kilograms divided by height in meters squared. The reliability of selfreported height and weight was assessed in a subsample of twins who participated in a follow-up study in 2014 July, whose body weight and height were measured by healthcare professionals. Intraclass correlations for measured versus self-reported weight and height were 0.89 and 0.94 respectively, which suggested good reliability of self-reported BMI. BMI was categorized according to the Asian standards as underweight $\left(<18.5 \mathrm{~kg} / \mathrm{m}^{2}\right)$, normal weight $(18.5-$ $23.9 \mathrm{~kg} / \mathrm{m}^{2}$ ), overweight (24 to $27.9 \mathrm{~kg} / \mathrm{m}^{2}$ ), and obese $\left(\geq 28 \mathrm{~kg} / \mathrm{m}^{2}\right)$.

Assessment of covariates. Potential covariates included age (18-79 years), region (south including Jiangsu, Zhejiang, Sichuan and Qinghai province, and Shanghai City, north including Heilongjiang Province, Tianjin, Beijing, and Qingdao City), zygosity (MZ and DZ), smoking status (current, past, and never smokers), and drinking status (current, past, and never drinkers).

\section{Statistical Methods}

All analyses were stratified by sex. Descriptive analyses were used to examine sex differences by study covariates and educational level, marital status, and obesity status. $P$-values were corrected for the correlation between co-twins using multinomial logistic regression for categorical variables and mixed-effects models for continuous variables.

\section{Linear Regression Models}

To determine the population (between-individual) effects, we used a mixed-effect linear regression model (Carlin et al., 2005) in all same-sex twins (without regard to twinpair membership) to analyze the association of educational level and marital status on BMI. Then, multinomial logistic regression analyses were used to analyze the association of educational level and marital status with overweight and obesity. Odds ratios (ORs) for overweight and obesity were compared with normal body mass. Models were estimated using correlated-cluster variance estimates to control for the dependence of observations within twin pairs. Covariates included age (continuous), region (south, north), zygosity (MZ and DZ), cigarette smoking (current, past, and never smokers), and alcohol drinking (current, past, and never drinkers). Within-pair analyses in MZ twin pairs were conducted first using fixed-effect linear regression, with BMI as a dependent variable and educational level, marital status, cigarette smoking, and alcohol drinking as independent variables. Then, conditional logistic regression was used to assess the extent to which educational level and marital status was associated with the risk of being overweight or obesity, controlling for cigarette smoking and alcohol drinking. Only pairs discordant for overweight or obesity were included in conditional logistic regression analyses. Discordant for overweight or obesity was defined as a BMI of $24 \mathrm{~kg} / \mathrm{m}^{2}$ or higher in one co-twin while being less than $24 \mathrm{~kg} / \mathrm{m}^{2}$ in another co-twin. The effect parameter for educational level and marital status could be estimated by controlling for genetic and environmental factors shared by co-twins using within-pair analyses. Sensitivity analyses in which models only adjusted for age, zygosity, and region were also conducted in order to examine the mediating effect of cigarette smoking and alcohol drinking for educational level, marital status, and obesity.

Marital status is different in younger than older adults and educational level is probably much higher in younger than in older age groups, so we further conducted a stratified analyses to assess the association of educational level and marital status with continuous BMI according to age group (age $\geq 45$ and age $<45$ ) in all twins and within MZ twin pairs. The age group-educational level interaction and age group-marital status interaction effect were tested to demonstrate whether the association between educational level/marital status and BMI differs as a function of age group. Analyses were performed using Stata11.2 (Stata Corp, College Station, TX). $P$-values were two-sided and statistical significance was assumed at $p<.05$.

\section{Structural Equation Model}

A structural equation model was used to examine the extent to which genetic or environmental variance were correlated across educational level, marital status, and BMI in this sample stratified by sex. Marital status was a binary variable, with married participants in one level and unmarried participants in another level (separated, divorced, or widowed participants were not included in analysis). All model-fitting analyses and maximum-likelihood parameter estimates were performed in OpenMx (Version 1.4).

First, we fitted a univariate structural equation model for educational level, marital status, and BMI to separate the observed phenotypic variances into genetic and environmental components: additive (A) genetic components and common (C) or unique (E) environmental components. Because educational level and marital status were categorical variables, heritability was estimated on the basis of a liability model (Verweij et al., 2012), which presumes an underlying, normally distributed susceptibility for the expression of the phenotype of interest with zero mean and unit variance. Categories were defined by thresholds on this underlying curve, such that the area under the curve reflects the proportion of the population in each category (McCaffery et al., 2009). A nested model for which A or $\mathrm{C}$ was equated to 
TABLE 1

Epidemiological Characteristics of the 20,896 Adult Twins

\begin{tabular}{|c|c|c|c|c|}
\hline & All twins $(N=20,896)$ & Male twins $(N=12,984)$ & Female twins $(N=7,912)$ & $p$-value ${ }^{a}$ \\
\hline Age, years (mean, $S D$ ) & $37.5(11.10)$ & 38.7 (11.45) & $35.4(10.18)$ & $<.001$ \\
\hline \multicolumn{5}{|l|}{ Age group, $n(\%)$} \\
\hline Age $<45$ & $15,962(76.4)$ & $9,440(72.7)$ & $6,522(82.4)$ & - \\
\hline Age $\geq 45$ & $4,934(23.6)$ & $3,544(27.3)$ & $1,390(17.6)$ & .552 \\
\hline Zgosity (MZ), n (\%) & $14,652(70.1)$ & $8,714(67.1)$ & $5,938(75.1)$ & $<.001$ \\
\hline $\mathrm{BMl}, \mathrm{kg} / \mathrm{m}^{2}$ (mean, SD) & $22.8(3.01)$ & $23.3(2.90)$ & $22.0(2.99)$ & $<.001$ \\
\hline \multicolumn{5}{|l|}{ Weight status, $n(\%)$} \\
\hline Underweight & $1,108(5.3)$ & $347(2.7)$ & $761(9.6)$ & $<.001$ \\
\hline Normal & $13,302(63.7)$ & $7,880(60.7)$ & $5,422(68.5)$ & - \\
\hline Overweight & $5,400(25.8)$ & $3,948(30.4)$ & $1,452(18.4)$ & $<.001$ \\
\hline Obese & $1,086(5.2)$ & 809 (6.2) & $277(3.5)$ & $<.001$ \\
\hline \multicolumn{5}{|l|}{ Region, $n(\%)$} \\
\hline East & $8,978(43.0)$ & $5,534(42.6)$ & $3,444(43.5)$ & - \\
\hline North & $11,918(57.0)$ & $7,450(57.4)$ & $4,468(56.5)$ & .364 \\
\hline \multicolumn{5}{|l|}{ Marital status, n (\%) } \\
\hline Not married & $4,861(23.3)$ & $2,853(22.0)$ & $2,008(25.4)$ & - \\
\hline Married & $15,550(74.4)$ & $9,831(75.7)$ & $5,719(72.3)$ & $<.001$ \\
\hline Live apart & $357(1.7)$ & $224(1.7)$ & $133(1.7)$ & .163 \\
\hline Widowed or divorced & $124(0.6)$ & $74(0.6)$ & $50(0.6)$ & .839 \\
\hline \multicolumn{5}{|c|}{ Educational attainment, $n$ (\%) } \\
\hline Primary & $2,559(12.2)$ & $1,749(13.5)$ & $810(10.2)$ & - \\
\hline Secondary & $13,001(62.2)$ & $8,722(67.2)$ & $4,279(54.1)$ & .357 \\
\hline Tertiary & $5,336(25.5)$ & $2,513(19.4)$ & $2,823(35.7)$ & $<.001$ \\
\hline \multicolumn{5}{|l|}{ Smoking status, n (\%) } \\
\hline Never & $14,860(71.1)$ & $7,046(54.3)$ & $7,814(98.8)$ & - \\
\hline Current & $5,731(27.4)$ & $5,656(43.6)$ & $75(0.9)$ & $<.001$ \\
\hline Former & $265(1.3)$ & $257(2.0)$ & $8(0.1)$ & $<.001$ \\
\hline \multicolumn{5}{|l|}{ Drinking status, $n(\%)$} \\
\hline Never & $16,419(78.6)$ & $8,621(66.4)$ & $7,798(98.6)$ & - \\
\hline Current & $4,251(20.3)$ & $4,160(32.0)$ & $91(1.2)$ & $<.001$ \\
\hline Former & $171(0.8)$ & $165(1.3)$ & $6(0.1)$ & $<.001$ \\
\hline
\end{tabular}

Note: $\mathrm{BMI}=$ body mass index, $\mathrm{DZ}=$ dizygotic, $\mathrm{MZ}=$ monozygotic, $\mathrm{SD}=$ standard deviation.

${ }^{a} p$-values were corrected for the correlation between co-twins using mixed-effects models for continuous variables and multinomial logistic regression for categorical variables.

zero was also fitted and Akaike information criterion (AIC) was used for comparison of goodness of fit of the models. Variance components of BMI were estimated with inclusion of age, region, smoking status, drinking status, educational level, and marital status as covariates.

Next, based on the best fit model we fitted the bivariate Cholesky decomposition models to calculate genetic $\left(r_{\mathrm{G}}\right)$ and environmental correlations $\left(r_{\mathrm{E}}\right)$ between educational level, marital status, and BMI and 95\% confidence intervals. Similarly, polychoric correlations between pairs of categorical variables were estimated on the basis of a liability model. All variance components of BMI were estimated with inclusion of age, region, smoking status, and drinking status as covariates.

\section{Results}

\section{Descriptive Characteristics of the Study Population}

A total of 10,448 complete adult twin pairs were included in this study, of whom $70.1 \%$ were MZ twin pairs. The sample characteristics are summarized in Table 1 . The mean age of this sample was 37.5 years and more than half were males (62.1\%). The mean BMI for the total population studied was $22.8 \mathrm{~kg} / \mathrm{m}^{2}$, and it was higher in men than in women. The majority of participants were married (74.4\%), being more prevalent in males than in females $(75.7 \%$ vs. $72.3 \%$, $p<.001)$. With respect to educational level, the percentage of participants who attained tertiary education was significantly higher in females than in males $(35.7 \%$ vs. $19.4 \%$, $p<.001)$.

\section{Associations Between Educational Level, Marital Status and Obesity}

Results from the sex-specific models treating twins as individuals are summarized in Table 2. After controlling for multiple socio-demographic and lifestyle factors, a significant correlation was observed between BMI, overweight, and obesity status, and educational level across both sexes, with the exception of males with secondary education, in which the likelihood for being obese was similar to those with primary education. However, some noticeable sex differences emerged from our study. The above-mentioned correlation was positive in males while negative in females. More specifically, males with secondary and tertiary education had increased BMI by $0.32 \mathrm{~kg} / \mathrm{m}^{2}$ and $0.50 \mathrm{~kg} / \mathrm{m}^{2}$ respectively compared to those with primary education $(p<.001)$. The corresponding values of females with secondary and tertiary education compared to primary-educated females were negative at $-0.58 \mathrm{~kg} / \mathrm{m}^{2}$ and $-1.11 \mathrm{~kg} / \mathrm{m}^{2}$ respectively $(p<.001)$. The odds ratios for secondary-educated men being overweight 
TABLE 2

Regression Analysis for BMI, Overweight, Obesity by Educational Level and Marital Status Treating Twins as Individuals ${ }^{\mathrm{a}}$

\begin{tabular}{|c|c|c|c|c|c|c|c|}
\hline \multirow[b]{2}{*}{ Gender } & \multirow[b]{2}{*}{ Predictor } & \multicolumn{2}{|c|}{$\mathrm{BMI}$} & \multicolumn{2}{|c|}{ Overweight } & \multicolumn{2}{|c|}{ Obesity } \\
\hline & & $\beta$ & $95 \% \mathrm{Cl}$ & OR & $95 \% \mathrm{Cl}$ & OR & $95 \% \mathrm{Cl}$ \\
\hline \multirow[t]{8}{*}{ Male } & $\begin{array}{l}\text { Educational level } \\
\text { Primary school (reference level) }\end{array}$ & & & & & & \\
\hline & Secondary school & 0.32 & $0.16,0.48$ & 1.30 & $1.12,1.52$ & 1.33 & $0.98,1.81$ \\
\hline & Tertiary school & 0.50 & $0.30,0.69$ & 1.57 & $1.30,1.89$ & 1.74 & $1.20,2.53$ \\
\hline & Marital status & & & & & & \\
\hline & Not married (reference level) & & & & & & \\
\hline & Married & 0.73 & $0.61,0.86$ & 1.98 & $1.73,2.27$ & 2.35 & $1.80,3.08$ \\
\hline & Live apart & 0.33 & $0.04,0.62$ & 1.52 & $1.07,2.14$ & 1.81 & $0.97,3.41$ \\
\hline & Windowed or divorced & 0.12 & $-0.37,0.61$ & 1.07 & $0.60,1.94$ & 0.89 & $0.21,3.83$ \\
\hline \multirow[t]{9}{*}{ Female } & Educational level & & & & & & \\
\hline & Primary school (reference level) & & & & & & \\
\hline & Secondary school & -0.58 & $-0.81,-0.35$ & 0.55 & $0.44,0.69$ & 0.48 & $0.32,0.71$ \\
\hline & Tertiary school & -1.11 & $-1.36,-0.85$ & 0.40 & $0.30,0.52$ & 0.36 & $0.22,0.59$ \\
\hline & Marital status & & & & & & \\
\hline & Not married (reference level) & & & & & & \\
\hline & Married & 0.62 & $0.47,0.76$ & 1.87 & $1.48,2.36$ & 2.16 & $1.33,3.52$ \\
\hline & Live apart & 0.30 & $-0.05,0.65$ & 0.84 & $0.45,1.58$ & 0.95 & $0.28,3.26$ \\
\hline & Windowed or divorced & 0.18 & $-0.38,0.74$ & 0.71 & $0.31,1.64$ & 0.35 & $0.05,2.58$ \\
\hline
\end{tabular}

Note: $\mathrm{BMI}=$ body mass index, $\mathrm{Cl}=$ confidence interval, $\mathrm{OR}=$ odds ratio.

${ }^{a}$ All regression models were adjusted for age, region, zygosity, smoking status, and drinking status.

\begin{tabular}{|c|c|c|c|c|c|}
\hline $\begin{array}{l}\text { Regress } \\
\text { Pairs }^{\mathrm{a}}\end{array}$ & is for BMI, Overweight, or Obe & cation & nd Marital S & IZ Twir & Twins as \\
\hline & & & & & obesity \\
\hline Gender & Predictor & $\beta$ & $95 \% \mathrm{Cl}$ & OR & $95 \% \mathrm{Cl}$ \\
\hline Male & $\begin{array}{l}\text { Educational level } \\
\text { Primary school (reference level) }\end{array}$ & & & & \\
\hline & Secondary school & 0.08 & $-0.18,0.34$ & 1.02 & $0.70,1.48$ \\
\hline & Tertiary school & 0.35 & $0.38,0.67$ & 1.18 & $0.75,1.86$ \\
\hline & Marital status & & & & \\
\hline & Not married (reference level) & & & & \\
\hline & Married & 0.26 & $0.10,0.41$ & 1.02 & $0.79,1.32$ \\
\hline & Live apart & -0.04 & $-0.37,0.29$ & 0.87 & $0.51,1.47$ \\
\hline & Windowed or divorced & -0.13 & $-0.66,0.41$ & 1.03 & $0.35,3.03$ \\
\hline Female & Educational level & & & & \\
\hline & Primary school (reference level) & & & & \\
\hline & Secondary school & 0.22 & $-0.21,0.65$ & 0.90 & $0.53,1.55$ \\
\hline & Tertiary school & 0.20 & $-0.28,0.67$ & 0.85 & $0.44,1.65$ \\
\hline & Marital status & & & & \\
\hline & Not married (reference level) & & & & \\
\hline & Married & 0.49 & $0.30,0.69$ & 1.59 & $1.03,2.45$ \\
\hline & Live apart & 0.46 & $0.04,0.87$ & 1.30 & $0.55,3.06$ \\
\hline & Windowed or divorced & 0.18 & $-0.48,0.83$ & 1.96 & $0.66,5.83$ \\
\hline
\end{tabular}

Note: $\mathrm{BMI}=$ body mass index, $\mathrm{Cl}=$ confidence interval, $\mathrm{OR}=$ odds ratio.

${ }^{a} A l l$ regression models were adjusted for smoking status and drinking status.

or obese was $1.30(p=.001)$ and $1.33(p=.067)$, while that of secondary educated women was 0.55 and 0.48 (both $p<$ $.001)$. Moreover, the odds ratios for tertiary-educated men being overweight was $1.57(p<.001)$ and for obesity was $1.74(p=.003)$, while the respective odds ratios for tertiaryeducated women were $0.40(p<.001)$ for being overweight and $0.36(p<.001)$ for obesity. As far as the relationship between marital status and obesity is concerned, married twins had significantly higher BMI than unmarried twins. Besides, married twins had increased odds for being overweight by $98 \%$ and $87 \%$ among males and females, respectively, compared to unmarried twins $(p<.001)$. The respective values for obesity were even higher, reaching
$135 \%(p<.001)$ and $116 \%(p=.002)$. In particular, men who lived apart also had higher BMI and higher odds for being overweight compared to unmarried men.

Further analyses treating twins as pairs revealed different results, which can be seen in Table 3. There was no significant association between educational level and BMI, overweight or obesity status across both sexes, with the exception of tertiary-educated MZ male twin pairs in which BMI was higher than primary educated ones. With respect to marital status, married twins had a significantly higher BMI in both sexes of MZ twin pairs compared to unmarried twins. The odds ratio for married twins being overweight or obese was only significant in female MZ 
twin pairs. The models of our primary analyses in which smoking status and drinking status were removed were reanalyzed as sensitivity analyses and the results are represented as Supplementary Table S1 and Table S2. However, there were no significant changes between the primary results and sensitivity results.

Further, we tested the statistically significant difference in effect of educational level and marital status on BMI between different age groups (from an interaction term between educational level/marital status and age group), and the results yielded a significant interaction between educational level and age group on BMI in both sexes. Educational level exerted a bigger effect on BMI in older men than in younger men while in women, educational level had less effect on BMI as age increased. We also had the ability to stratify analyses according to age group within MZ twin pairs. For marital status, married twins had a significantly higher BMI compared to unmarried twins, except for older females. Regarding educational level, we found that higher educational level was associated with a higher BMI in both older females and males. Testing for interaction between educational level/marital status and age group revealed similar patterns in all twins (Table 4).

\section{Genetic and Environmental Contributions to the So- cioeconomic Disparities in Body Mass Index}

Before examining genetic and environmental factors common across educational level, marital status and BMI, we first estimated the genetic and environmental contributions to each phenotype. The additive genetic/common environment/unique environment (ACE) model offered the best fit for BMI, educational level (in both male and female twins), and marital status (only in male twins); dropping genetic (A) or common environment (C) decreased the fit significantly, with the $p$-value for differences in model fits all larger than 0.05 . On the contrary, genetic effects did not contribute significantly to marital status in female twins, whereas common and unique environmental variance did. The heritability analyses for educational level, marital status and BMI are shown in Table S3.

Table 5 shows the genetic and environmental contributions to phenotypic correlations in this twin sample. The genetic and common environmental correlations between educational level and BMI were significantly negative in females, while positive in males. However, unique environmental correlations were only significant in males. Marital status correlated with BMI with a strong positive common environmental and a somewhat weaker but still highly significant unique environmental correlation in both sexes.

\section{Discussion}

At the individual level, we found clear educational- and marital status-based differences in BMI, overweight, and obesity status among Chinese twins that replicated the pre- vious studies (Dinsa et al., 2012; Kilicarslan et al., 2006). However, our twin fixed-effect analyses yielded generally a weak association between educational level and BMI, overweight or obesity status, although in male MZ twins, the association between tertiary education and BMI tended to suggest a significant effect. Regarding marital status, we found a positive association among MZ twins in both sexes. Genetic modeling analyses showed that genetic and common environmental correlations confounded the relationship between education and BMI in females, while the strong relationship between BMI and marital status in both sexes was due to both common and unique environmental correlations.

According to our results, at the individual level, a significant positive association between educational level and BMI, overweight and obesity status was found in male twins, while in female twins, the association was in the opposite direction, with a lower BMI and a lower risk of overweight and obesity in higher educated females. The sex differences of education on BMI have been noted before. Accumulated evidence suggests an inverse association between education and obesity mostly among women, while in men this association is less consistent (Kowalkowska et al., 2014; Noh et al., 2014; Vernay et al., 2009). The difference in findings between men and women might be related to the differential costs of higher body size; for example, the cost of overweight or obesity in terms of reduced labor market opportunities (Sarlio-Lahteenkorva et al., 2004) or increased discrimination seems to be higher for women than for men. We also found that educational level had an interaction with age on BMI. For men, educational level exerted a bigger effect on BMI as age increased, while for women, educational level had less effect on BMI as age increased. This may be explained by sex difference roles and consciousness of increased age. For higher educated men, they may be occupied with work and engaged in more social activities (e.g., dinner parties, even in an older age group) that means they have less exercise and a more unhealthy diet. But for women, as their age increases, the importance of appearance decreases (Liang et al., 1999) and they may pay less attention to their body shape, so the negative effect of educational level on BMI is weakened.

When treating twins as pairs, the observed association between education and BMI disappeared in fixed-effect analyses among female MZ twins, which was in agreement with the previous studies (Fujiwara \& Kawachi, 2009; Silventoinen et al., 2004). With regard to males, tertiary education remained a significant effect on BMI and subsequent genetic analyses revealed that besides genetic and common environmental factors, unique environmental factors not shared by twin pairs only contributed to the relationship between education and BMI in male twins but not in female twins. This suggested that the educational effect on BMI in female twins we observed in the individual level analyses was due to selection processes related to confounding 


\section{TABLE 4}

Regression Analysis for the Association Between BMI and Educational Level and Marital Status Stratified by Age Group in MZ Twins Treating Twins As Pairs

\begin{tabular}{|c|c|c|c|c|c|c|c|c|c|c|c|}
\hline \multirow[b]{3}{*}{ Gender } & \multirow[b]{3}{*}{ Predictor } & \multicolumn{5}{|c|}{ All twins ${ }^{a}$} & \multicolumn{5}{|c|}{ Within MZ twins ${ }^{\mathrm{b}}$} \\
\hline & & \multicolumn{2}{|c|}{ Age $<45$} & \multicolumn{2}{|c|}{ Age $\geq 45$} & \multirow{2}{*}{$\begin{array}{l}p \text { for } \\
\text { interaction }\end{array}$} & \multicolumn{2}{|c|}{ Age $<45$} & \multicolumn{2}{|c|}{ Age $\geq 45$} & \multirow{2}{*}{$\begin{array}{l}\text { p for } \\
\text { interaction }\end{array}$} \\
\hline & & $\beta$ & $95 \% \mathrm{Cl}$ & $\beta$ & $95 \% \mathrm{Cl}$ & & $\underline{\beta}$ & $95 \% \mathrm{Cl}$ & $\bar{\beta}$ & $95 \% \mathrm{Cl}$ & \\
\hline \multirow[t]{8}{*}{ Male } & $\begin{array}{l}\text { Educational level } \\
\text { Primary school (reference level) }\end{array}$ & & & & & & & & & & \\
\hline & Secondary school & 0.17 & $-0.63,0.41$ & 0.21 & $-0.00,0.41$ & .056 & -0.21 & $-0.60,0.19$ & 0.26 & $-0.09,0.61$ & .049 \\
\hline & Tertiary school & 0.23 & $-0.03,0.50$ & 0.68 & $0.29,1.06$ & .001 & 0.02 & $-0.42,0.45$ & 0.82 & $0.22,1.42$ & .017 \\
\hline & Marital status & & & & & & & & & & \\
\hline & Not married (reference level) & & & & & & & & & & \\
\hline & Married & 0.53 & $0.39,0.67$ & 0.60 & $0.29,0.90$ & .153 & 0.18 & $0.01,0.35$ & 0.64 & $0.23,1.04$ & .703 \\
\hline & Live apart & 0.25 & $-0.09,0.60$ & -0.11 & $-0.64,-0.42$ & .143 & -0.12 & $-0.51,0.27$ & 0.27 & $-0.38,0.92$ & .992 \\
\hline & Windowed or Divorced & -0.92 & $-2.36,0.52$ & 0.31 & $-0.23,0.86$ & .227 & -0.24 & $-1.84,1.36$ & 0.18 & $-0.48,0.83$ & .040 \\
\hline \multirow[t]{8}{*}{ Female } & $\begin{array}{l}\text { Educational level } \\
\text { Primary school (reference level) }\end{array}$ & & & & & & & $-1.04,1.00$ & 0.10 & $-0.40,0.00$ & .040 \\
\hline & Secondary school & -0.77 & $-0.10,-0.47$ & -0.29 & $-0.72,1.14$ & .008 & -0.39 & $-0.91,0.13$ & 1.42 & $0.62,2.22$ & .000 \\
\hline & Tertiary school & -1.42 & $-1.73,-1.11$ & -0.65 & $-1.27,-0.02$ & .003 & -0.42 & $-0.97,0.15$ & 1.56 & $0.49,2.62$ & .001 \\
\hline & Marital status & & & & & & & & & & \\
\hline & Not married (reference level) & & & & & & & & & & \\
\hline & Married & 0.52 & $0.36,0.67$ & 0.60 & $-0.47,1.67$ & .398 & 0.52 & $0.32,0.71$ & -0.73 & $-2.27,0.81$ & .210 \\
\hline & Live apart & 0.12 & $-0.27,0.50$ & 0.62 & $-0.70,1.94$ & .422 & 0.38 & $-0.07,0.84$ & -0.47 & $-2.23,1.29$ & .116 \\
\hline & Widowed or divorced & -0.23 & $-1.26,0.81$ & 0.53 & $-0.73,1.79$ & .814 & -0.71 & $-2.01,0.58$ & -0.80 & $-2.52,0.93$ & .090 \\
\hline
\end{tabular}

Note: $\mathrm{MZ}=$ monozygotic, $\mathrm{Cl}=$ confidence interval.

aAll regression models were adjusted for age, region, zygosity, smoking status and drinking status.

${ }^{\circ}$ All regression models were adjusted for smoking status and drinking status. 


\section{TABLE 5}

Bivariate Genetic Analyses of the Estimated Genetic and Environmental Correlation Coefficients for Phenotype Pairs in Both Sexes $^{\mathrm{a}}$

\begin{tabular}{|c|c|c|c|c|c|c|c|}
\hline Gender & Phenotype & $r_{A}$ & $95 \% \mathrm{Cl}$ & $r_{C}$ & $95 \% \mathrm{Cl}$ & $r_{E}$ & $95 \% \mathrm{Cl}$ \\
\hline \multirow[t]{2}{*}{ Male } & BMI - Educational level & 0.015 & $0.006,0.952$ & 0.029 & $0.021,0.034$ & 0.062 & $0.015,0.068$ \\
\hline & $\mathrm{BMI}$ - Marital status & 0.132 & $-0.096,0.364$ & 0.426 & $0.322,0.542$ & 0.092 & $0.015,0.171$ \\
\hline \multirow[t]{2}{*}{ Female } & BMI - Educational level & -0.369 & $-0.585,-0.148$ & -0.696 & $-0.734,-0.660$ & 0.005 & $-0.075,0.085$ \\
\hline & BMI —Marital status & - & - & 0.434 & $0.372,0.500$ & 0.17 & $0.084,0.252$ \\
\hline
\end{tabular}

Note: $r_{\mathrm{A}}=$ genetic correlation between two phenotypes; $r_{\mathrm{C}}=$ common environmental correlation between two phenotypes; $r_{\mathrm{E}}=$ unique environmental correlation between two phenotypes.

$\mathrm{BMI}=$ body mass index; $\mathrm{Cl}=$ confidence interval

a Variance components were estimated with BMI corrected for age, region, smoking status and drinking status.

from genetic factors or common rearing environment. Another factor that seems related to this concern about physical appearance among MZ female twin pairs was peer effects within pairs of twins. Several studies indicate that peer effects might differ between men and women. For instance, Dinand et al. (Webbink et al. 2010) found a statistically significant effect of sibling's schooling on BMI for women but not for men, which suggested that having a higher educated sister reduces the probability of being overweight.

Concerning marital status, married twins had a higher BMI and a higher risk for being overweight or obese in both sexes, compared to unmarried twins. This finding was consistent with other studies conducted in Colombian (Davila et al., 2013) and Greek (Tzotzas et al., 2010) adults, and Brazilian adolescents (Silva, 2013). Further, in our MZ twins fixed-effect analyses, after cancelling genetic and early family environmental factors, we continued to observe this association, which indicates that the association between marital status and BMI is independent of these factors. However, our findings stand in contrast to a study conducted in middle-aged Danish twins, which reported that twins discordant for marital status did not differ for levels of BMI (Osler et al., 2008). The difference in findings between the Danish study and our study could be due to differences in the study sample, statistical analyses models and adjusted confounding factors. Nevertheless, it is premature to conclude that marital status is causally associated with BMI. The associations reported in our twin fixed-effect analyses might also be due to residual confounding by unmeasured covariates, rather than to the causal effect of marriage on BMI.

The common environment had a strong effect on marital status, while genetic and unique environment had a much smaller effect. We found no genetic effect on marital status among female twins, which means this behavior is mainly decided by environment factors. Results from our bivariate genetic analyses suggested that both common and unique environmental factors explained the association between marital status and BMI. The unique environmental contribution suggested that environmental factors specific to twins, and not common across twins, accounted for the association between marital status and BMI. This result is entirely consistent with our fixed-effect analyses results, which demonstrate a greater BMI in married $\mathrm{MZ}$ twins relative to their unmarried co-twins. A direct environmental effect of marriage on BMI that is independent of genetic effects could occur, for example, through reduction in weight perception or increase in appetite and sustaining of a positive energy balance. It is also possible that the unique environmental correlation reflects the effect of a third unmeasured variable on both marriage and BMI, such as energy intake. Taken together, these findings suggest that cumulative experiences across the life-course, including those after marriage, and not just early shared life experiences, shape adult health.

This study is the first that reports on educational level and marital status associated with obesity in the adult Chinese population using a large twin sample from CNTR. Twin studies provide insights into whether the association between educational level, marital status, and obesity in previous studies is because of shared environment, common genetic factors, or other pathways associated with individual twins. Furthermore, our findings also expand the knowledge of the genetic and environmental contribution to these associations.

Meanwhile, it is important to note the limitations of the present study. First, the data on BMI was based on selfreported height and weight, which may be inaccurate. In this study, however, the correlations between self-reported and measured weight and height values were high, at about 0.90 . In addition, we had no detailed information on energy intake and physical activity, so the possibility of residual confounding by these unmeasured covariates cannot be excluded. Finally, we were not able to analyze the direction of causation due to cross-sectional design.

\section{Conclusion}

In conclusion, education was associated with increased BMI in males, while in females, the association was in the opposite direction in individual-level analyses. However, in fixed-effect analyses cancelling the effect of genetic and early family environment, the associations were less robust between males and females. Married twins tended to have higher BMI than unmarried twins, independent of genetic and shared environmental factors in both sexes. 
Environmental factors specific to twins might account for this association. The findings of the present study provide evidence that obesity could be faced by tackling specific subgroups such as high educated males and married people. High educational level is an important issue and it should be promoted, along with nutritional education, during early life, mainly in men.

\section{Ethical Approval}

All procedures performed in studies involving human participants were in accordance with the ethical standards of the Biomedical Ethics Committee at Peking University, Beijing, China, and with the 1964 Helsinki Declaration and its later amendments or comparable ethical standards.

\section{Informed Consent}

Informed consent was obtained from all individual participants included in the study.

\section{Acknowledgments}

The authors gratefully acknowledge the cooperation of the $\mathrm{CDC}$ twin project staff in nine provinces.

\section{Funding}

This study was supported by the Special Fund for Health Scientific Research in Public Welfare (201502006, 201002007) and a Key Project of Chinese Ministry of Education (310006).

\section{Disclosure of Interests}

None.

\section{Supplementary material}

To view supplementary material for this article, please visit https://doi.org/10.1017/thg.2018.8

\section{References}

Boing, A. F., \& Subramanian, S. V. (2015). The influence of area-level education on body mass index, waist circumference and obesity according to gender. International Journal of Public Health, 60, 727-736.

Carlin, J. B., Gurrin, L. C., Sterne, J. A., Morley, R., \& Dwyer, T. (2005). Regression models for twin studies: A critical review. International Journal of Epidemiology, 34, 1089-1099.

Davila, E. P., Quintero, M. A., Orrego, M. L., Ford, E. S., Walke, H., Arenas, M. M., ... Pratt, M. (2013). Prevalence and risk factors for metabolic syndrome in Medellin and surrounding municipalities, Colombia, 2008-2010. Preventive Medicine, 56, 30-34.

Dinsa, G. D., Goryakin, Y., Fumagalli, E., \& Suhrcke, M. (2012). Obesity and socioeconomic status in developing countries: A systematic review. Obesity Reviews, 13, 10671079.
Fujiwara, T., \& Kawachi, I. (2009). Is education causally related to better health? A twin fixed-effect study in the USA. International Journal of Epidemiology, 38, 1310-1322.

Gupta, R., Guptha, S., Gupta, V. P., Agrawal, A., Gaur, K., ... Deedwania, P. C. (2012). Twenty-year trends in cardiovascular risk factors in India and influence of educational status. European Journal of Preventive Cardiology, 19, 12581271.

Heath, A. C., Berg, K., Eaves, L. J., Solaas, M. H., Corey, L. A., Sundet, J., ... Nance, W. E. (1985). Education policy and the heritability of educational attainment. Nature, 314, 734736.

Hermann, S., Rohrmann, S., Linseisen, J., May, A. M., Kunst, A., Besson, H., ... Peeters, P. H. (2011). The association of education with body mass index and waist circumference in the EPIC-PANACEA study. BMC Public Health, 11, 169.

Johnson, W., McGue, M., Krueger, R. F., \& Bouchard, T. J. (2004). Marriage and personality: A genetic analysis. Journal of Personality and Social Psychology, 86, 285-294.

Kilicarslan, A., Isildak, M., Guven, G. S., Oz, S. G., Tannover, M. D., Duman, A. E., ... Sozen, T. (2006). Demographic, socioeconomic and educational aspects of obesity in an adult population. Journal of the National Medical Association, 98, 1313-1317.

Kowalkowska, J., Wadolowska, L., Weronika, W. J., Slowinska, M. A., \& Niedzwiedzka, E. (2014). Socioeconomic status and overweight prevalence in polish adolescents: The impact of single factors and a complex index of socioeconomic status in respect to age and sex. Iranian Journal of Public Health, 43, 913-925.

Li, L., Gao, W., Yu, C., Lv, J., Cao, W., Zhan, S., ... Hu, Y. (2013). The Chinese national twin registry: An update. Twin Research and Human Genetics, 16, 86-90.

Liang, W., Shediac-Rizkallah, M. C., Celentano, D. D., \& Rohde, C. (1999). A population-based study of age and gender differences in patterns of health-related behaviors. American College of Preventive Medicine, 17, 8-17.

McCaffery, J. M., Papandonatos, G. D., Bond, D. S., Lyons, M. J., \& Wing, R. R. (2009). Gene X environment interaction of vigorous exercise and body mass index among male Vietnam-era twins. American Journal of Clinical Nutrition, 89, 1011-1018.

McGue, M., Osler, M., \& Christensen, K. (2010). Causal inference and observational research: The utility of twins. Perspectives on Psychological Science, 5, 546-556.

Nau, C., Schwartz, B. S., Bandeen-Roche, K., Liu, A., Pollak, J., Hirsch, A., ... Glass, T. A. (2015). Community socioeconomic deprivation and obesity trajectories in children using electronic health records. Obesity (Silver Spring), 23, 207212.

Noh, J. W., Jo, M., Huh, T., Cheon, J., \& Kwon, Y. D. (2014). Gender differences and socioeconomic status in relation to overweight among older Korean people. PLoS One, 9, e97990.

Osler, M., McGue, M., Lund, R., \& Christensen, K. (2008). Marital status and twins' health and behavior: An analysis of middle-aged Danish twins. Psychosomatic Medicine, 70, 482-487. 
Sarlio-Lahteenkorva, S., Silventoinen, K., \& Lahelma, E. (2004). Relative weight and income at different levels of socioeconomic status. American Journal of Public Health, 94, 468-472.

Schousboe, K., Willemsen, G., Kyvik, K. O., Mortensen, J., Boomsma, D. I., Cornes, B. K., ... Kaprio, J. (2003). Sex differences in heritability of BMI: A comparative study of results from twin studies in eight countries. Twin Research, 6 , 409-421.

Silva, D. A. (2013). Socioeconomic inequalities in abdominal obesity in Brazilian female adolescents: A national-based study. European Journal of Pediatrics, 172, 1665-1670.

Silventoinen, K., Jelenkovic, A., Sund, R., Yokoyama, Y., Hur, Y. M., Cozen, W., ... Kaprio, J. (2017). Differences in genetic and environmental variation in adult BMI by sex, age, time period, and region: An individual-based pooled analysis of 40 twin cohorts. American Journal of Clinical Nutrition, 106, 457-466.

Silventoinen, K., Sarlio-Lahteenkorva, S., Koskenvuo, M., Lahelma, E., \& Kaprio, J. (2004). Effect of environmental and genetic factors on education-associated disparities in weight and weight gain: A study of Finnish adult twins. American Journal of Clinical Nutrition, 80, 815-822.

Sobal, J., Hanson, K. L., \& Frongillo, E. A. (2009). Gender, ethnicity, marital status, and body weight in the United States. Obesity (Silver Spring), 17, 2223-2231.

Sobal, J., Rauschenbach, B., \& Frongillo, E. A. (2003). Marital status changes and body weight changes: A US longitudinal analysis. Social Science \& Medicine, 56, 1543-1555.

Tzotzas, T., Vlahavas, G., Papadopoulou, S. K., Kapantais, E., Kaklamanou, D., ... Hassapidou, M. (2010). Marital status and educational level associated to obesity in Greek adults: Data from the National Epidemiological Survey. BMC Public Health, 10, 732.

Vernay, M., Malon, A., Oleko, A., Salanave, B., Roudier, C., Szego, E., ... Castetbon, K. (2009). Association of socioeconomic status with overall overweight and central obesity in men and women: The French Nutrition and Health Survey 2006. BMC Public Health, 9, 215.

Verweij, K. J., Mosing, M. A., Zietsch, B. P., \& Medland, S. E. (2012). Estimating heritability from twin studies. Methods in Molecular Biology, 850, 151-170.

Wang, B., Gao, W., Yu, C., Cao, W., Lv, J., Wang, S., ... Li, L. (2015). Determination of zygosity in adult Chinese twins using the $450 \mathrm{~K}$ methylation array versus questionnaire data. PLoS One, 10, e123992.

Wardle, J., \& Griffith, J. (2001). Socioeconomic status and weight control practices in British adults. Journal of Epidemiology and Community Health, 55, 185-190.

Wardle, J., \& Steptoe, A. (2003). Socioeconomic differences in attitudes and beliefs about healthy lifestyles. Journal of Epidemiology and Community Health, 57, 440-443.

Webbink, D., Martin, N. G., \& Visscher, P. M. (2010). Does education reduce the probability of being overweight? Journal of Health Economics, 29, 29-38.

Xi, B., Liang, Y., He, T., Reilly, K. H., Hu, Y., Wang, Q., ... Mi, J. (2012). Secular trends in the prevalence of general and abdominal obesity among Chinese adults, 1993-2009. Obesity Reviews, 13, 287-296. 